\title{
FLEXIBILIDADE ORÇAMENTÁRIA DEVE SER USADA COM MODERAÇÃO
}

Em 31 de agosto de 2016, em cumprimento ao disposto no art. $35, \$ 2^{\circ}$, III, do Ato das Disposições Transitórias da Constituição, foi apresentada a proposta de orçamento federal para 2017. E nos próximos dias devem ser apresentadas as propostas orçamentárias da maior parte dos demais entes da federação, conforme dispõe a legislação própria de cada um.

Infelizmente é apresentada mais uma vez sem que tenha sido precedida da aprovação da Lei de Diretrizes Orçamentárias, que tem a função de balizar o conteúdo da lei orçamentária, o que prejudica e desvaloriza o sistema de planejamento orçamentário definido pela Constituição e Lei de Responsabilidade Fiscal. Fato comum em épocas de turbulência política, como a que ora se apresenta, mas que vem ocorrendo com indesejável frequência, como se tem observado nos últimos anos.

Desnecessário ressaltar a importância do sistema de planejamento governamental e, mais ainda, da lei orçamentária que nele se insere, já reconhecida como a mais importante após a Constituição, o que já ressaltei muitas vezes nesta coluna, pois nela se define o que vai ser feito com o dinheiro público.

E não é demais voltar a enfatizar a necessidade de que se lute para aproximar cada vez mais o que consta do orçamento com os desejos da população, tornando-o uma peça que efetivamente reflita, de forma democrática e transparente, o que se pretende fazer com os recursos que todos entregamos para o Estado.

Mais ainda, é fundamental que se cumpra o que nele foi aprovado, sendo este um aspecto de suma relevância, e para o qual o ordenamento jurídico ainda não tem dado uma resposta satisfatória.

É antigo o debate no âmbito do Direito Financeiro sobre a "natureza jurídica" da lei orçamentária e seu caráter "autorizativo" ou "impositivo", a qual já nos re- 
ferimos anteriormente em outras colunas, ${ }^{1}$ e não é o caso de voltar ao tema neste texto, cujo objetivo será tão somente esclarecer algumas questôes relevantes em torno do assunto.

Recentemente, a aprovação da Lei 13.332, de 10.9.2016, gerou polêmica ao alterar dispositivo do orçamento federal em vigor (LOA 2016, Lei 13.255, de 14.1.2016), dando margem a interpretaçôes equivocadas a respeito de um tema que vale a pena esclarecer e trazer para o debate: o da flexibilidade orçamentária. Mesmo porque, no recente caso que levou ao impeachment da Presidente da República, uma das acusaçôes envolve justamente um dos instrumentos de flexibilidade orçamentária, o que deixa evidente a sua importância.

Sendo a lei orçamentária uma previsão de arrecadação e definição dos gastos que ocorrerão no exercício financeiro subsequente, torna-se evidente que seu cumprimento não tem como se realizar de modo absolutamente fiel, sendo natural e compreensível que o orçamento executado não será idêntico ao que foi aprovado. São muitas as intercorrências havidas desde as previsões que são feitas para a elaboração da peça orçamentária até o final de sua execução. Várias alterações nos fatos econômicos e sociais, nem sempre previsíveis e mensuráveis, exigem mecanismos que permitam ajustes ao longo da execução orçamentária.

Daí por que existem os instrumentos de flexibilidade orçamentária, com a finalidade de viabilizar alterações que se mostrem necessárias no orçamento.

A grande questão que se coloca é justamente a dimensão que se deve dar ao uso desses instrumentos. Em diferentes ordenamentos jurídicos a flexibilidade orçamentária se mostra ora mais ampla, ora mais restrita, com conflitos de diferentes características e graus de profundidade entre os Poderes Executivo e Legislativo. ${ }^{2} \mathrm{O}$ Brasil não escapa a estas questôes. E a distribuição de poderes durante a fase de execução orçamentária é elemento central das engrenagens que movem o direito orçamentário, pois é a partir das competências para flexibilizar o orçamento público que se determina a distribuição do poder financeiro. ${ }^{3}$

1 Entre outras, na coluna Orçamento não pode mais ser uma peça de ficção, publicada em 2 de junho de 2015 (e que consta neste livro).

2 O que permite identificar, como bem sistematizado por Gabriel Lochagin, os instrumentos de flexibilidade com participação parlamentar forte, caso em que sua autorização depende de aprovação prévia e específica do Poder Legislativo; e outros com participação parlamentar fraca, nos quais a aprovação parlamentar ou não é prévia ou não é específica (A flexibilidade da execução orçamentária. Dissertação de Mestrado. Faculdade de Direito da USP, 2012, p. 95 e seguintes).

3 Algumas considerações sobre o tema estão na coluna Durante as eleiçôes, pense bem para quem vai entregar a chave do cofre, publicada em 26 de agosto de 2014 e que consta neste livro. 
O orçamento é uma lei, sendo, portanto, evidente que deve e se espera seja cumprida. Tendo em vista as peculiaridades da lei orçamentária, já referidas, uma eventual impossibilidade de sua execução nos exatos termos em que foi aprovada não justifica alterações de tal forma significativas que a desfigure por completo, sob pena de inutilizá-la como instrumento de planejamento, de condução da atividade financeira da administração pública e inviabilizando o controle. É tornar a lei orçamentária "letra morta" e verdadeira "peça de ficção", como chega a ser conhecida, alcunha que não se pode mais permitir que seja merecedora.

Para isso, é necessário que os instrumentos de flexibilidade orçamentária sejam limitados e seu uso moderado, de modo a fazer com que sejam utilizados para "cumprir o que foi estabelecido pela lei orçamentária em seu aspecto essencial [com] os ajustes nas previsões e programações orçamentárias durante o curso de sua execução, [mantendo-se] a necessidade de se cumprir fielmente o orçamento, do modo como aprovado pelo Poder Legislativo, com as imprescindíveis alterações que se façam necessárias ao longo do exercício financeiro, sem, com isso, descaracterizá-lo e fazer dele uma peça de ficção". Embora indispensáveis, em face da natureza da lei orçamentária, os instrumentos de flexibilidade orçamentária devem ser sempre utilizados para alcançar os fins consignados na peça orçamentária, como bem colocado por Rodrigo Faria. ${ }^{5}$

E quais seriam esses instrumentos?

Vale destacar alguns, mais utilizados e representativos, o que será feito a seguir.

Os principais instrumentos de flexibilidade destinados a alterar dotaçôes previstas no orçamento aprovado são os créditos adicionais, previstos nos artigos $40 \mathrm{a}$ 46 da Lei 4.320, de 1964. Há três tipos: os suplementares, os especiais e os extraordinários. Os créditos suplementares são abertos para o reforço de dotações que se mostraram insuficientes, os especiais atendem a despesas que não tinham dotação orçamentária específica, e os extraordinários são admitidos para despesas imprevisíveis e urgentes, conforme dispõe o artigo $167, \$ 3^{\circ}$, da Constituição. Para cada uma dessas modalidades há diferentes procedimentos legislativos de aprovação.

Os créditos extraordinários admitem abertura por medida provisória (artigo 62, $₫ 1^{\mathrm{o}}, d$, da Constituição). A aprovação parlamentar é, portanto, posterior à abertura do crédito, quando o Poder Legislativo é chamado a apreciar a medida de

4 Como já escrevi em CONTI, José Mauricio. A autonomia financeira do Poder Judiciário. MP Editora, 2006. p. 93. Destaquei.

5 FARIA, Rodrigo Oliveira. Natureza jurídica do orçamento e flexibilidade orçamentária. Dissertação (Mestrado). Faculdade de Direito da Universidade de São Paulo. São Paulo: 2009. p. 268. 
urgência, daí o enfraquecimento de suas possibilidades de controle. Os créditos suplementares e os especiais, por sua vez, devem ser abertos por lei, porém com uma exceção diretamente relevante ao caso aqui analisado.

Existe a possibilidade de que a própria lei orçamentária anual preveja uma autorização prévia ao Poder Executivo para a abertura de créditos suplementares dentro de limites quantitativos e respeitadas as condiçōes previstas. Esse instrumento, denominado margem de remanejamento, é largamente utilizado pelos entes da federação, e confere poderes importantes ao Executivo para manejar o orçamento público. Esta autorização é prevista no art. 7º, I, da referida Lei 4.320, o qual, com o intuito de agilizar a execução orçamentária, trata da possibilidade de na lei orçamentária haver dispositivo autorizando o Poder Executivo a abrir créditos suplementares, limitando a importância e observando os requisitos legais. Permite-se, assim, que seja dispensada a necessidade de um projeto de lei para abrir créditos suplementares, que podem ser baixados por ato do Executivo, desde que respeitados os termos da autorização que lhe foi concedida pela lei orçamentária.

Em face da importância que tem como instrumento de modificação dos orçamentos aprovados, é recomendável que as margens de remanejamento sejam autorizações bem limitadas, tanto em vista dos percentuais permitidos quanto da observância de estritas condiçôes para sua abertura. Comentando estas autorizações prévias à abertura de créditos suplementares, Pontes de Miranda já advertia: “[t] udo aconselha que, no caso dos créditos suplementares, se determinem de antemão os serviços para os quais podem ser abertos e a quanto podem montar de per si e em quais condições". 6 Somente é possível o exercício excepcional do poder de modificar as dotações orçamentárias pela via dos créditos suplementares se respeitados os limites da autorização contida na lei orçamentária. Estabelecer os limites e as condições do emprego das margens de remanejamento "trata-se de competência parlamentar. Mais do que isso, tem-se que tal autorização constitui competência exclusiva do Poder Legislativo, que não a poderia delegar a outro Poder sob pena de renunciar a suas prerrogativas constitucionais"?

Esse dispositivo estava previsto no orçamento federal de 2015 (Lei 13.115, de 20 de abril), que estabelecia limites de remanejamento de até $20 \%$, mediante o emprego de recursos provenientes de fontes especificadas no artigo $4^{\circ}$ desta lei, que

6 PONTES DE MIRANDA, Francisco. Comentários à Constituição da República dos Estados Unidos do Brasil. Rio de Janeiro: Guanabara, 1936. t. 1, p. 547-8.

7 LOCHAGIN, Gabriel. A flexibilidade da execução orçamentária. Dissertação (Mestrado). Faculdade de Direito da Universidade de São Paulo. São Paulo: 2012, p. 135. 
deveriam observar, além do limite quantitativo, diversos requisitos, entre os quais a compatibilidade com a obtenção da meta de resultado primário prevista na LDO (caput do mesmo artigo $4^{\circ}$ ).

Consta também do orçamento federal de 2016 autorização semelhante, porém com o limite de $10 \%$ para abertura dos créditos suplementares, previsto no artigo $4^{\circ}$. A necessidade de cumprimento da meta de resultado primário já constava da lei original. A modificação da lei orçamentária de 2016, veiculada pela Lei 13.332 deste ano, alterou o percentual para $20 \%$, o mesmo que havia sido estabelecido para 2015, sem modificar o requisito de cumprimento da meta de superávit primário da LDO. Ou seja, aumentou-se o percentual, ampliando a flexibilidade, o que não é desejável em face do que foi exposto. Perdeu-se a oportunidade de limitar o uso indevidamente amplo das margens de remanejamento, o que importou em recuo do que poderia ter sido um avanço com a tentativa, ora frustrada, de reduzir o percentual que estava vigente na lei orçamentária de 2015. No entanto, não houve alteração no que se refere à exigência de se observar a meta fiscal, cujo descumprimento deu origem à ilegalidade que caracterizou um dos crimes de responsabilidade motivadores do recente impeachment da Presidente. Não houve neste aspecto, portanto, modificação que importasse em alterar o fato que foi tipificado como conduta ilegal, como chegou a ser difundido.

É relevante ressaltar a necessidade de que os demais entes da federação fiquem atentos a esta questão, pois muitos abrem margens de remanejamento elevadíssimas, com percentuais demasiadamente altos, e sem impor outras condições restritivas. Um verdadeiro despropósito que precisa cessar, pois promove uma delegação de poderes do Legislativo ao Executivo, fazendo com que a lei orçamentária praticamente deixe de ter natureza de lei para passar a, de fato, tornar-se ato do Poder Executivo, contrariando o que determina a Constituição.

Há ainda outros instrumentos importantes de flexibilização da execução orçamentária, com destaque para o contingenciamento, sobre o qual já discorremos na coluna Hora é de apertar o cinto e contingenciar gastos, publicada em 11 de março de $2014 .{ }^{8}$

Com a finalidade de empregar os créditos orçamentários em montantes inferiores aos previstos, promove-se a limitação de empenho e movimentação financeira, terminologia usada pela Lei de Responsabilidade Fiscal para tratar dos contingenciamentos (ou "bloqueios") de recursos. De acordo com a programação orçamentária e financeira do ente, deve-se proceder à suspensão da execução do

8 A coluna consta neste livro. 
gasto tendo em vista, por exemplo, as expectativas de diminuição da arrecadação. Trata-se, portanto, de um instrumento de ajuste da execução da despesa aos fluxos de receitas. A ausência de autorização legislativa anterior específica para os atos de contingenciamento faz deles atos com fraco controle parlamentar.

Mas há diversos outros mecanismos de flexibilidade voltados não a gastar menos, mas a gastar mais ou de forma diversa da inicialmente prevista. É o caso, por exemplo, das transposições, remanejamentos e transferências de recursos, que realocam recursos de uma categoria da programação a outra ou de um órgão a outro, conforme previsto na Constituição Federal, no artigo 167, VI. A diferença entre eles é tratada em alguns trabalhos a respeito do orçamento público, que procuram diferenciá-los. Caso se trate de alteração de dotaçôes em razão de mudanças na organização administrativa, há remanejamento, como quando se extingue um órgão e se deslocam seus recursos a outro (modificação no plano institucional); caso se reveja a prioridade de programas, fala-se em transposição (modificação no plano programático); e caso se transfiram recursos entre distintas categorias de despesa tem-se propriamente a transferência (modificação no plano dos gastos). ${ }^{9}$

Há que se registrar ainda a chamada reserva de contingência, "dotação global não especificamente destinada a determinado órgão, unidade orçamentária, programa ou categoria econômica, cujos recursos serão utilizados para a abertura de créditos adicionais" (Decreto-lei 200/1967, art. 91), e que deve constar da lei orçamentária anual, sendo destinada ao atendimento de passivos contingentes e outros riscos e eventos fiscais imprevistos, cujo uso deve ser estabelecido na lei de diretrizes orçamentárias (Lei de Responsabilidade Fiscal, art. 5º, II). Com a reserva de contingência, torna-se mais fácil atender a necessidades imprevistas, evitando a necessidade de se anularem dotações específicas já existentes e modificar o orçamento aprovado.

Como se pode notar, não faltam mecanismos para alterar o orçamento, talvez até em demasia. $\mathrm{O}$ ideal seria que fossem utilizados somente quando necessário, o que não se verifica na realidade, em uma prática que se perpetua e parece que não vai cessar.

O fato é que os orçamentos são leis por demais relevantes, é preciso garantir que sejam cumpridos da forma mais fiel possível, pois somente assim poderão ser levados a sério.

9 Ver MACHADO JR., José Teixeira; REIS, Heraldo da Costa. A Lei 4.320 comentada e a lei de responsabilidade fiscal. 31. ed. Rio de Janeiro: IBAM, 2002/2003. p. 108. 